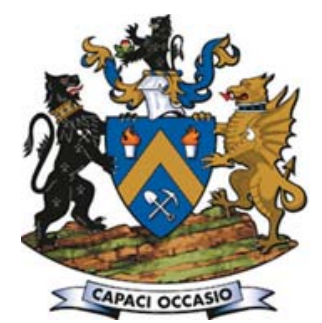

\title{
The new Cullinan AG milling circuit - a narrative of progress
}

\author{
by L. Musenwa*, T. Khumalo*, M. Kgaphola*, S. Masemola*, \\ and G. van Wyk ${ }^{\dagger}$
}

\section{Synopsis}

In 2017, Petra Diamonds completed the construction and commissioning of a modern, fit-for-purpose diamond processing plant at Cullinan Diamond Mine (CDM). The design of CDM's milling circuit is unconventional in that it comprises an autogenous (AG) mill with a grate discharge with large ports, low-revolution jaw crushers, and high-pressure grinding roll crushers with large operating gaps. In this paper we review the design to provide guidance on what is expected from the milling circuit and to demonstrate how the design aims to address challenges experienced in the old plant, which was based on staged crushing technology. We assessed the performance of the CDM AG milling circuit from commissioning and early production stages to examine its impact along multiple dimensions. In the assessment we sought to understand the lessons from our milling circuit regarding diamond liberation, energy consumption, and the future of diamond processing as a whole.

\section{Keywords}

kimberlite processing, autogenous milling, high-pressure grinding roll, diamond liberation, diamond damage.

\section{Introduction}

Cullinan Diamond Mine (CDM), previously known as Premier Mine, is an underground diamond mine owned by Petra Diamonds. Petra Diamonds is a leading independent diamond mining group and a growing supplier of rough diamonds to the international market. Petra Diamonds is listed on the Main Market of the London Stock Exchange under the ticker 'PDL'. Petra's total resource of 305 million carats ranks third by size after De Beers and ALROSA (Petra Diamonds, 2018).

CDM was established in 1902. The mine rose to prominence in 1905 , when the 3106 carat Cullinan Diamond - the largest rough diamond of gem quality ever found - was discovered there. The mine has produced over 750 stones that are larger than 100 carats and more than a quarter of all the world's diamonds that are larger than 400 carats. Cullinan is renowned as a source of large, high-quality gem diamonds, including Type II stones, as well as being the world's most important source of very rare blue diamonds (Petra Diamonds, 2018).

In September 2017, MDM Engineering completed the construction and commissioning of a modern, fit-for-purpose processing plant at CDM, with a throughput capacity of $6 \mathrm{Mt} / \mathrm{a}$. This has replaced the previous plant at CDM, which was originally commissioned in 1947 and which had undergone numerous refurbishments over the years. Due to its age and operational complexity, it had become expensive to maintain, requiring significant stay-in-business capex, and costly to operate, particularly given its large 26 ha footprint. The plant was also mostly based on old crushing technology, which is known to be inefficient for the recovery of large stones. The design of the new plant was therefore aimed at improving recoveries at a lower cost and reducing diamond breakage. The new plant was also designed to use more environmentally friendly processes, which is vital for the long-term sustainable future of the mine.

The new plant utilizes gentler processing methods - comminution by attrition and abrasion instead of extensive staged crushing. The new comminution methods used are AG milling and high-pressure grinding rolls (HPGRs), which are expected to reduce diamond breakage and improve recoveries across the full spectrum of diamonds, including the larger/exceptional stones for which the mine is renowned. The top cut size of $75 \mathrm{~mm}$ will cater for diamonds of more than 3000 carats, such as the Cullinan Diamond. The plant has a much smaller footprint of just $4 \mathrm{ha}$, and the engineering infrastructure has been significantly reduced.
* Petra Cullinan Diamond Mine, South Africa.

† Thyssenkrupp, Johannesburg, South Africa.

(C) The Southern African Institute of Mining and Metallurgy, 2019. ISSN 2225-6253. This paper was first presented at the Diamonds - Source to Use 2018 Conference, 11-13 June 2018, Birchwood Hotel and OR Tambo Conference Centre, Jet Park, Johannesburg, South Africa. 


\section{The new Cullinan AG milling circuit - a narrative of progress}

\section{AG milling in diamond processing}

Traditionally, Southern African diamond processing plants are designed to include various stages of crushing to liberate diamonds from the host rock. These types of plants have been operated to process kimberlite deposits in Southern Africa over a number of years, and include the old CDM plant which was commissioned in 1947. The crushers in a conventional plant use compression and impact forces between two steel surfaces to break the feed material. Although the crushers are optimized to operate at the maximum possible crushing gap, there is still the potential for breaking diamonds between the steel surfaces.

Furthermore, cone crusher products, having steep product distributions, are associated with poor liberation of diamonds from the host rock (Daniel, 2010).

In recent years AG milling has been slowly introduced in diamond processing in Southern Africa. AG milling is an established comminution process (van Niekerk, 2013), and has been used in Russia over the past 40 years. The Russian experience cannot, however, be translated directly to the processing requirements in Southern Africa. Russian methods have historically focused on maximizing diamond liberation (Janse, 2007). The Russian government regulations require very strict auditing of operational performance to ensure that the orebody is being completely 'exhausted', typically down to $1 \mathrm{~mm}$.

Catoca mine in Angola was the first significant Southern African diamond operation to install AG mills. ALROSA, the Russia-based diamond producer, is a major shareholder in the Catoca mine. The first diamonds were recovered in 1997 and the plant was expanded in 2005, raising the combined processing capacity to over $10 \mathrm{Mt}$ of ore per annum. All of the Catoca plants are equipped with AG mills as the main comminution devices. The Catoca mine's main orebody or pipe consists of volcanogenic-sedimentary rocks, with the inner ring of the vertical pipe made up of porphyric kimberlite, while the central part is filled with kimberlitic breccias. This type of material can be classified as relatively soft and is therefore ideally suited for AG mill processing (van Niekerk, 2013).

In 2012 Karowe mine was successfully commissioned by Lucara in Botswana. The Karowe plant is equipped with an AG mill as the major comminution device. The Karowe operation has been modified and optimized over a number of years to process various material fractions through the plant. At Karowe the material varies from soft and friable to very competent. The operation has been very successful, especially as the world's second-largest gem diamond, at 1111 carats, was recovered in November 2015 (Lucara, 2018).

\section{The new CDM milling plant design}

The CDM comminution circuit was designed to reduce diamond breakage and improve recoveries across the full spectrum of diamonds; including the larger/exceptional stones for which the mine is renowned. When applied correctly, AG milling offers a diamond-friendly comminution environment (Daniel, Bellingan, and Rauscher, 2016). The purpose of any comminution process is to liberate or expose locked-up valuable minerals within the host rock or gangue.
This is an essential step in mineral processing as proper liberation allows for maximum recovery of minerals in the downstream processes. Undergrinding leads to inefficient recoveries (Steyn, 2011) and overgrinding, especially in the diamond processing context, leads to major value loss due to breakage of the final product. Knowledge of the ideal product size is essential in the design of any comminution circuit.

The new plant has been designed to improve the efficiency of material flow, thereby significantly lowering operating costs. The new plant's footprint is significantly less than that of the old CDM processing plant. Some of the comparisons to the old plant are summarized in Table I.

\section{New plant process flow}

The new CDM plant process flow is illustrated in Figure 1. The new mill plant is designed to handle run-of-mine (ROM) ore as well as reclaimed tailings. The ROM ore is conveyed from a $5000 \mathrm{t}$ capacity ROM silo to the mills. The reclaimed and recirculated ore is conveyed from a $3000 \mathrm{t}$ capacity silo to the mills. The ROM ore from the silos is blended with reclaimed tailings in the desired proportion for optimum grinding. The plant is designed for $6 \mathrm{Mt} / \mathrm{a}$, and will initially process $4 \mathrm{Mt} / \mathrm{a}$ ROM plus $2 \mathrm{Mt} / \mathrm{a}$ reclaimed ore. The mill is designed for an overall fresh feed rate of $750 \mathrm{t} / \mathrm{h}$ feeding two mills in parallel. This is blended as follows:

> $500 \mathrm{t} / \mathrm{h}$ ROM ore

> $250 \mathrm{t} / \mathrm{h}$ reclaimed ore.

Each mill is designed for a fresh feed rate of $375 \mathrm{t} / \mathrm{h}$ and a $152 \%$ circulating load.

The mill discharge slurry $(-150 \mathrm{~mm})$ flows onto a dedicated scalping vibrating grizzly installed for each mill. The grizzly oversize is conveyed to the jaw crushers. The jaw crusher product is conveyed to the recycle ore silo. The jaw crushers were designed with a bypass option to return excess load to the mills or bypass the crushers during maintenance.

\begin{tabular}{|c|c|c|}
\hline \multicolumn{3}{|c|}{$\begin{array}{l}\text { Table I } \\
\text { Comparison of the old and new CDM plants }\end{array}$} \\
\hline & Old plant & New AG milling plant \\
\hline Throughput per annum & $\begin{array}{c}2.8 \mathrm{Mt} \mathrm{ROM} \\
2.5 \mathrm{Mt} \text { tailings }\end{array}$ & $\begin{array}{l}\text { 6.0 Mt ROM capacity } \\
\text { Initial feed: } \\
4.0 \mathrm{Mt} \text { ROM } \\
2.0 \mathrm{Mt} \text { tailings }\end{array}$ \\
\hline Total footprint & Approx. 27 ha & Approx. 4 ha \\
\hline \multicolumn{3}{|c|}{ Major installed equipment } \\
\hline Conveyors & 151 belts $(15 \mathrm{~km})$ & 22 belts $(3 \mathrm{~km})$ \\
\hline Conveyor transfer points & 179 & 32 \\
\hline Screens & 88 & 22 \\
\hline Pumps & 121 & 7 \\
\hline Crushers & 18 & 4 (excluding mills) \\
\hline Feeders & 21 & 14 \\
\hline Substations & 17 & 2 \\
\hline Electrical motors & 589 & 84 \\
\hline \multicolumn{3}{|c|}{ Improved electricity efficiency } \\
\hline Power consumption & $22.5 \mathrm{MW}$ & $25.0 \mathrm{MW}$ \\
\hline Power consumption per ton & 4.7 & 4.2 \\
\hline \multicolumn{3}{|c|}{$\begin{array}{ll}\text { Improved water consumption } \\
\end{array}$} \\
\hline $\mathrm{m}^{3}$ per ton & 3.5 & 1.2 \\
\hline
\end{tabular}




\section{The new Cullinan AG milling circuit - a narrative of progress}

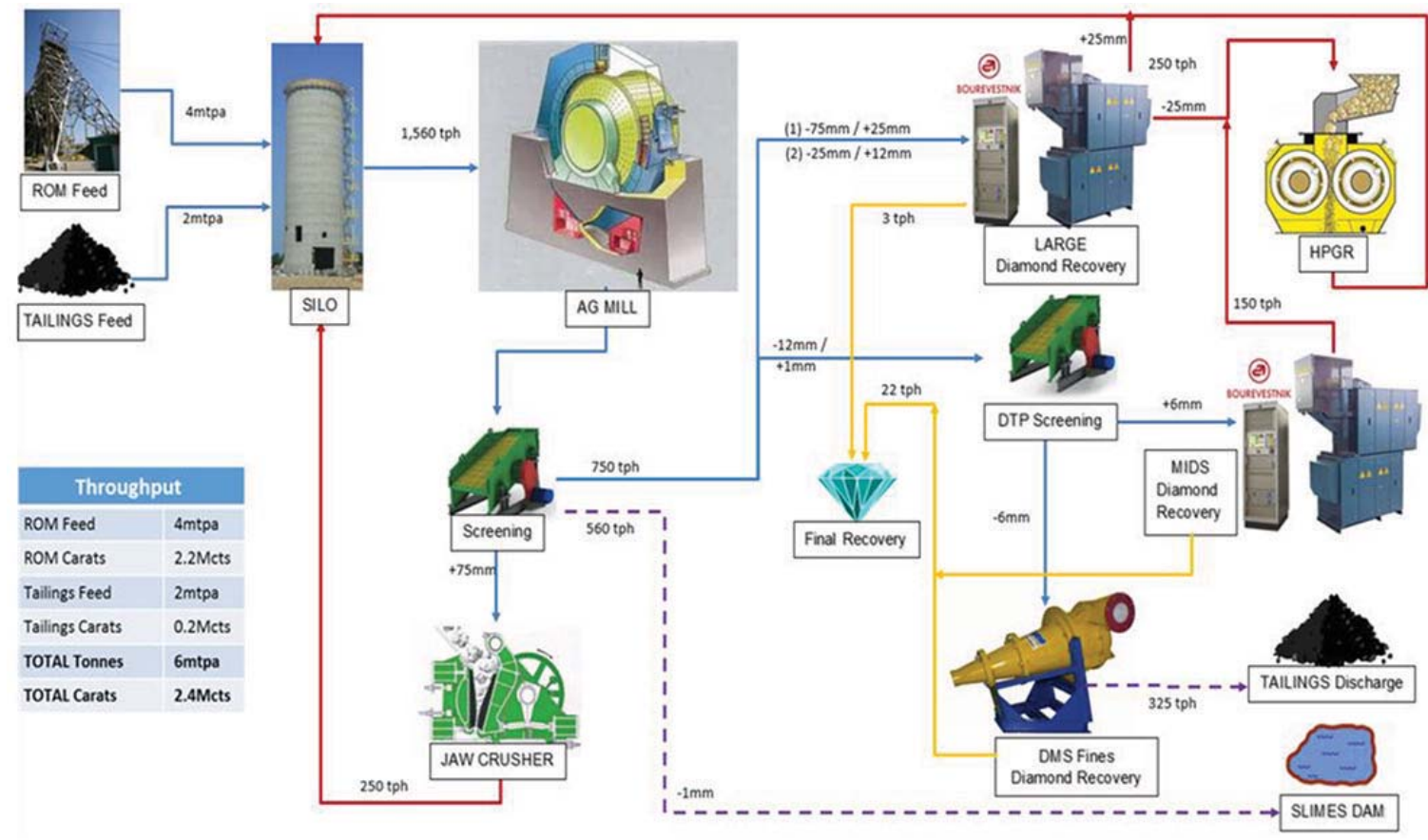

Figure 1-Schematic of the new CDM mill plant process flow (Petra Diamonds, 2015)

The grizzly screens undersize $(-75 \mathrm{~mm})$ gravitates to dedicated mill product sizing screens for each mill stream. The sizing screen oversize $(-75+12 \mathrm{~mm})$ is conveyed to the primary X-ray luminescence (XRL) sorting plant for recovery of large diamonds. The sizing screen undersize gravitates to the de-sliming section for the removal of $-1 \mathrm{~mm}$ slimes through a series of trommels and dewatering vibrating screens. The $-12+1 \mathrm{~mm}$ product from the de-sliming section is conveyed to the dense medium separation (DMS) and mids diamond recovery sections.

The main purpose of the XRL section is to sort the -75 $+12 \mathrm{~mm}$ diamonds in the mill product. The feed to XRL is concentrated on the basis of luminescence by five large ( -75 $+25 \mathrm{~mm})$ and five coarse $(-25+12 \mathrm{~mm})$ diamond XRL sorters supplied by Bourevestnik (BV). The coarse diamond XRL sorter tailings $(-25+12 \mathrm{~mm})$ are conveyed to the HPGR crushing section. This coarse fraction can be bypassed to the recycle silo if so desired. The large diamond XRL sorter tailings $(-75+25 \mathrm{~mm})$ are conveyed back to the recycle silo or, if required, are directed to the HPGR crushers. Concentrates from the large diamond XRL sorters and the coarse diamond XRL sorters are combined and conveyed to the final recovery section for further processing.

The HPGR crushing section is designed to incorporate two crushers to assist with the rock breakage before the material is returned to the mill. Initially, only one HPGR unit was installed. The second unit will be added as a future installation. Coarse XRL tailings $(-25+12 \mathrm{~mm})$ and the mids diamond recovery tailings $(-12+6 \mathrm{~mm})$ feed this section. The option exists to route the large XRL tailings $(-75+25 \mathrm{~mm})$ to the HPGR section if this size fraction builds up in the circuit and requires further crushing. The crushed product from this section reports to the recycle silo. The HPGR section is also equipped with a bypass option to bypass excess material past the HPGR or bypass material when the crusher is offline.

The DMS treats the $-6+1 \mathrm{~mm}$ size fraction. The $-12+6$ $\mathrm{mm}$ size fraction is separated on the DMS preparation screen and treated through the mids diamond recovery plant, which consists of four BV sorters. The $-6+1 \mathrm{~mm}$ ) size fraction is treated though four $510 \mathrm{~mm}$ DMS cyclones. The concentrate from the DMS cyclones and the mids diamond recovery is conveyed to the secondary recovery section. The mids diamond recovery tailings are conveyed to the HPGR section. The DMS tailings are discarded.

In the final recovery plant at CDM, concentrates from the XRL large and coarse recovery, mids diamond recovery, and the DMS are treated using BV sorters for further concentration of diamonds.

\section{Drop weight test (DWT) results}

The JKTech drop weight test (JKDW) is used to identify rockspecific parameters that are then used for simulating and predicting equipment performance. The drop weight tests are used in conjunction with SAG mill comminution (SMC) test results to model comminution equipment (Weier, 2013). The output from this work can be used when modelling mill throughput, energy consumption, and product size distribution, relative to ore hardness. Effects of changes in the in feed size distribution to the mill as well as operating variables such as mill filling and critical speed can also be examined.

Material testing was conducted on the most representative ore fractions from the CDM orebody, using just two samples representing grey kimberlite and hypabassal kimberlite. The results of these tests are displayed in Table II. 


\section{The new Cullinan AG milling circuit - a narrative of progress}

\begin{tabular}{|c|c|c|c|c|c|}
\hline \multirow[t]{3}{*}{ Sample } & \multicolumn{4}{|c|}{ Breakage type } & \multirow[t]{3}{*}{ Relative density } \\
\hline & \multicolumn{3}{|c|}{ Impact } & \multirow{2}{*}{$\begin{array}{c}\text { Abrasion } \\
\mathrm{Ta}\end{array}$} & \\
\hline & A & b & $A^{*} b$ & & \\
\hline $\begin{array}{l}\text { Grey kimberlite } \\
\text { Hypabassal }\end{array}$ & 88.80 & 0.45 & 39.96 & 0.45 & 2.68 \\
\hline $\begin{array}{l}\text { kimberlite } \\
\text { Blend }\end{array}$ & $\begin{array}{l}71.90 \\
78.60\end{array}$ & $\begin{array}{l}0.55 \\
0.51\end{array}$ & $\begin{array}{l}39.55 \\
39.71\end{array}$ & $\begin{array}{l}0.55 \\
0.51\end{array}$ & $\begin{array}{l}2.80 \\
2.75\end{array}$ \\
\hline
\end{tabular}

The lower the Ta value, the more competent the ore, i.e. the higher the resistance to abrasive comminution. Figure 2 shows that the CDM blend resides in the most competent region of the current kimberlite database. The shaded areas represent the domains of the CDM and Jwaneng kimberlites for comparative purposes. This is illustrative of the order-ofmagnitude difference in throughput and power consumption of CDM compared with Jwaneng ores. As a further reference point, Karowe mine has $\mathrm{T}_{\mathrm{a}}$ values ranging from 0.26 to 1.56 (van Niekerk, 2013) and Williamson diamond mine is off the scale with Ta values of 1.6 plus.

\section{CDM mill specifications}

The two Polysius mills installed at CDM were supplied by ThyssenKrupp. Table III shows the specification for both mills. Material properties were used by CITIC-SMCC Process Technology to specify and design the grinding circuit.
The AG mills were designed to incorporate a discharge grate with very large ports with openings ranging from $170 \mathrm{~mm}$ to $220 \mathrm{~mm}$ in size. Convectional port sizes are less than $45 \mathrm{~mm}$ for diamond processing plants and can be as large as $100 \mathrm{~mm}$ for other applications (Napier-Munn et al., 1999). The difference in the discharge port of the CDM mill is illustrated in Figure 3. The open area of the discharge grate is $8.36 \%$. With no previous experience of such large port sizes,

Table III
CDM mill specifications

\begin{tabular}{l|c}
\hline Mill parameter & Specification \\
\hline Type & Wet AG mill, grate discharge type \\
\hline Design & Shell supporting with slide shoe bearings \\
\hline Make/supplier & Polysius/ThyssenKrupp \\
\hline Diameter (inside shell) & $9.20 \mathrm{~m}$ \\
\hline Effective grinding length & $4.88 \mathrm{~m}$ \\
\hline Percentage of critical speed & $60-90 \%$ \\
\hline Required motor power & $6400 \mathrm{~kW}$ \\
\hline Motor speed & $995 \mathrm{r} / \mathrm{min}$ \\
\hline Max. operating ball charge & $0 \%$ \\
\hline Feed size & $-450 \mathrm{~mm}$ \\
\hline Circulating load & $130-200 \%$ \\
\hline Mill liner material & Steel liners \\
\hline $\begin{array}{l}\text { Mill shell liner thickness } \\
\text { (incl. lifter) }\end{array}$ & $278.4 \mathrm{~mm}$ \\
\hline Discharge grate & Full ported, $170 \mathrm{~mm}$ ports \\
\hline
\end{tabular}

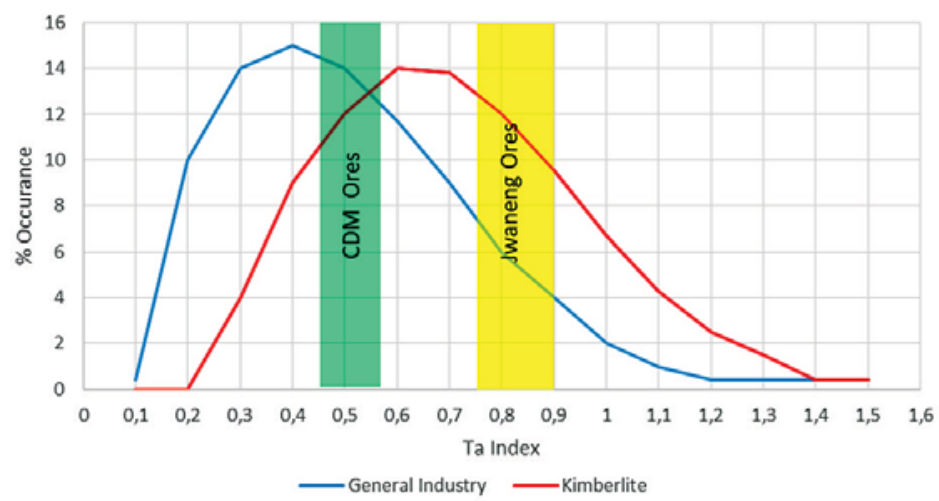

Figure 2-Ta index distribution of the CDM kimberlite in comparison with general industry and kimberlite Ta values (Claassen, 2006)

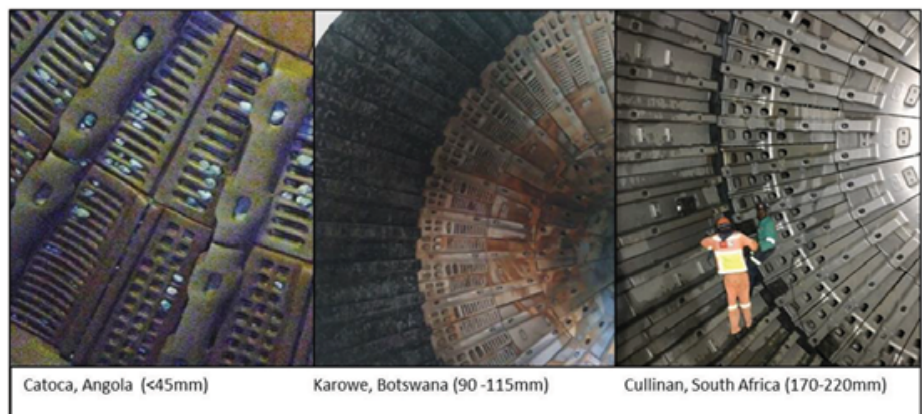

Figure 3-A comparison between the discharge ports of the new CDM plant and other diamond processing mills in Africa. The new CDM mill plant has larger ports in comparison with Russian and existing African mill installations 


\section{The new Cullinan AG milling circuit - a narrative of progress}

the CDM mill circuit was expected to deliver higher throughputs and high recirculation loads of $130-200 \%$. The reason for large port sizes is the presence of large stones, i.e. value protection.

The mill liner design was optimized to limit impact collisions inside the grinding chamber and enhance the attrition and abrasion forces, as shown in Figure 4. Particular care was taken to satisfy all of the special requirements specified in the equipment data-sheet. The liner design was enhanced in the pulp chamber to accommodate the flow of large particles.

\section{HPGR specifications}

The CDM HPGR specifications are displayed in Table IV. The HPGR is one of the notable features from the old plant design that was in incorporated in the new design. The first HPGR in a kimberlitic operation was installed at CDM (then called the Premier Mine) in 1987. The HPGR was included in the new mill circuit because of its ability to minimize diamond damage in comparison to impact crushing. Comminution takes place primarily through interparticle crushing due to large operating gaps, which are usually bigger than the feed particles (Ntsele and Sauermann, 2007). The CDM HPGR was designed to operate at a gap of $55 \mathrm{~mm}$ to ensure optimal value protection.

\section{Commissioning}

Commissioning of the new plant was started in the third quarter of 2017. The old plant was shut down before the construction of the new plant was completed. Some of the old sections were utilized while construction of the new plant continued. The new processing plant incorporated the fines DMS section $(-6+1 \mathrm{~mm})$ which was commissioned in 2012 as part of the dump treatment plant. Because this DMS section was already operational, the plant could commission some of the major comminution equipment even before the large diamond recovery section was completed. This meant that large particles in the circuit could either be trucked back to the mill or stockpiled to be processed later.

Start-up of the AG mills was relatively simple without any significant issues. The mills were ramped up to full

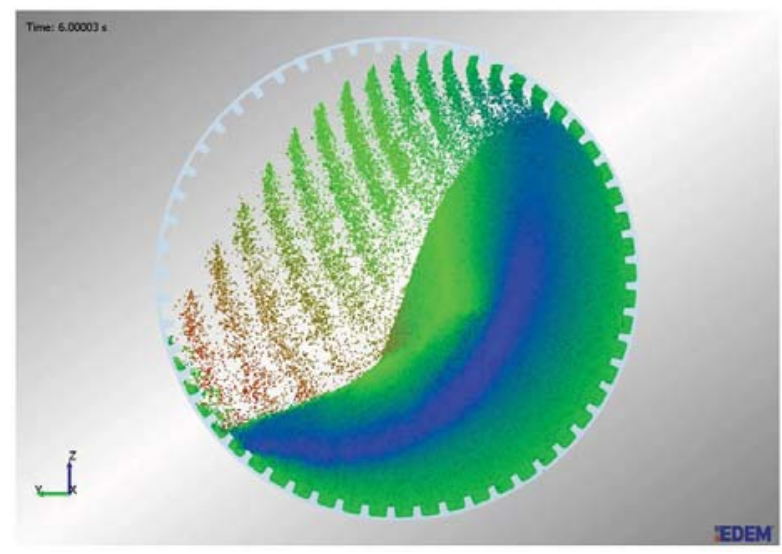

Figure 4-Simulated particle trajectory at approx. $78 \%$ critical speed. About $1.5 \%$ of the total energy is consumed by normal collisions and 98.5\% by tangential collisions (attrition) (ME Elecmetal, 2016) operating speed and achieved maximum power draw levels. This meant that despite the large pebble openings and open area the mill could still be operated at a significant load level.

Initially, the circuit was not operated with the full recycle load due to the delay in the completion of the large diamond recovery section. At the time it was therefore impossible to determine the final operating conditions in the circuit. Once the large diamond recovery section was completed the plant was able to be operated as per the intended design. The commissioning team did not immediately achieve the design capacity and some fine tuning and adjustment were required to improve performance. The performance test was, however, successfully completed in November 2017. The production team continues to optimize the process to find the ideal recipe for all conditions. The following sections highlight some of the challenges and successes achieved during commissioning of the plant.

\section{Low availability of classification and dewatering equipment}

The most significant issues during plant start-up were classification and dewatering equipment breakdowns. The grizzly screens and trommel screens in the circuit suffered frequent breakdowns during the commissioning process.

The grizzly screens, which are located immediately after the two mills, posed the most significant challenge in the comminution circuit. The grizzly screen panels experienced a number of failures due to the impact and load of large particles of up to $170 \mathrm{~mm}$ discharged from the mills. A newly developed deck and new panel design were supplied to improve the reliability of the process. The screening apertures were also reduced from $75 \mathrm{~mm}$ to $55 \mathrm{~mm}$ because some particle shapes in the mill product resulted in very large particles reporting to the XRL section. The mine team, in conjunction with the panel and screen suppliers, continues to develop the screening panels and structure of the grizzly screens to improve the reliability of the process.

The plant is designed to utilize motorized trommel screens to dewater the mill discharge pulp before the final fines screening stage. The trommel screens are very efficient at removing the water from the processing stream, but the units were initially not mechanically reliable. Modifications were made to the support wheels to improve the availability of these units.

\section{Difficulties in processing reclaimed tailings material}

The plant was designed to treat a significant portion of reclaimed tailings material to supplement ROM ore. The introducing of this fraction of material was very challenging for the commissioning team.

Table IV

\section{DM HPGR specifications}

\begin{tabular}{|l|c|}
\hline HPGR parameter & Specification \\
\hline Make/supplier & Polysius/ThyssenKrupp \\
Roll diameter & $2.8 \mathrm{~m}$ \\
Roll width & $0.5 \mathrm{~m}$ \\
Peripheral roll speed & $2.8 \mathrm{~m} / \mathrm{s}$ \\
Operating gap & $55 \mathrm{~mm}$ \\
Circuit capacity & $750 \mathrm{t} / \mathrm{h}$ \\
\hline
\end{tabular}




\section{The new Cullinan AG milling circuit - a narrative of progress}

The first challenge was the handling and conveying of the material, which is sometimes fine, sticky, and wet, and causes blockages in transfer chutes. The second challenge was that a significant portion of this material is finer than $2.5 \mathrm{~mm}$. Material in this size fraction is heavily influenced by the flow of water in the mill and is discharged quite quickly without effective grinding (Steyn, 2011). This has at times caused feed rates higher than $350 \mathrm{t} / \mathrm{h}$ to DMS, resulting in the DMS being unable to treat all the mill product and subsequent stockpiling of DMS feed material. The third significant challenge in treating tailings has been the presence of dense, old recovery tailings which resulted in high yield to the final recovery.

Solutions to these challenges have been implemented with a large degree of success. The tailings feed grizzly and conveyor transfer points were changed to cater for the fine, wet, and sticky material. The sizing screen panels were changed to $8 \mathrm{~mm}$ square apertures to redirect the $-12+8 \mathrm{~mm}$ mids diamond recovery feed to the XRL section, which has excess processing capacity. Lastly, the dense, old recovery tailings are carefully blended with old DMS tailings to reduce the recovery yields to manageable levels.

\section{Unreliability of mill load measurements}

The load in the AG mill is determined by load cells installed under the supporting bearings on the non-drive end of the mill. This load level signal is used to run the mill under an automated control loop to optimize the feed rate to the mill. The load cells only give the relative mass of the load in the mill and not an absolutely mass. Measured load values tend to be unreliable due to the scaling of the control signal and/or load reading variations caused by changes in the density of the feed material, i.e. variations in bulk density of the finer recycled material relative to the coarser ROM ore. Figure 5 illustrates the difference in the mill loading for the same load reading. The mill feed rate control is dependent on this load value, and for this reason it is essential to have the most accurate measurement possible. This load information is not only essential for optimizing the throughput of the mill, but can also be used to ensure the mill is operated in the most diamond-friendly way.

\section{Mill feed segregation}

Segregation occurs in both the ROM silo and recycle silo, due to the orientation and layout of the ROM and recycle feed belts. The segregation results in the coarse fractions from the ROM and recycle silo reporting to mill no. 1 , and a high percentage of the fine fractions reporting to mill no. 2, as can be seen in Figure 6. This is a design oversight which can have significant production and financial implications, for two reasons. The first is that segregation impacts the performances of the two mills, due to mill no. 1 receiving excess grinding medium in the form of large particles and mill no. 2 being deprived of sufficient grinding medium. The second reason, which is financial, is that completely eliminating the segregation in the silos would be difficult and costly. To address this challenge the mine team has developed different operating recipes for each mill. In addition, the commissioning team closed some of the ports on the grate discharge of mill no. 2 with rubber plugs to enable the mill to reach operating load by reducing the discharge rate of the finer feed to this mill. The installed plugs reduced the total open area of mill no. 2 from $8.36 \%$ to $7.38 \%$. Plugging the discharge had no significant effect of the performance, and the mill is still operating with these plugged holes.

\section{Mill product analysis}

The mill plant design does not cater very well for physical sampling of the mill feed and product streams. Due to the plant layout and physical constraints it is extremely difficult to take samples of the mill feed and discharge product. This constraint necessitated the installation of four Split-Online cameras, one on the feed conveyor and one on each of the three mill product streams, shortly after the commissioning of the plant, to track important size fractions within the process. Figure 7 illustrates the data that can be generated using the Split-Online system. With this system, the plant team is able to keep accurate track of the particles reporting to each process. The system has been subsequently developed to quickly track any deviations from the expected size fractions in each product stream and initiate appropriate corrective

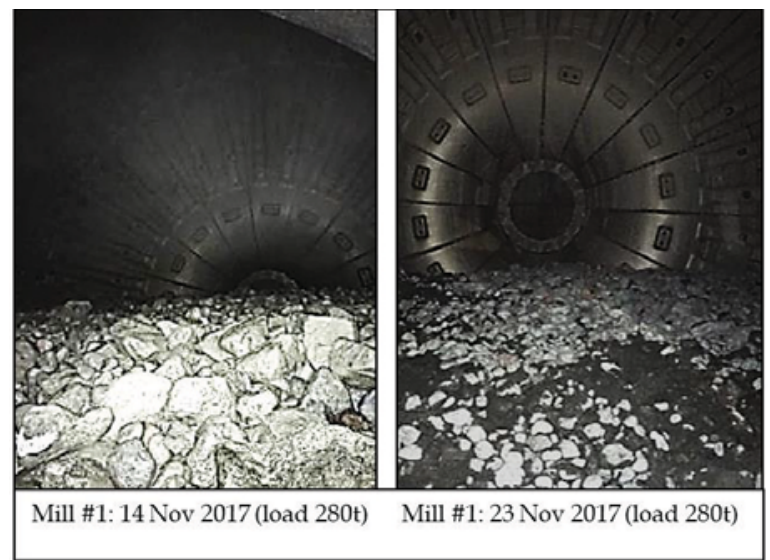

Figure 5-Illustration of the unreliability of load cell readings. The two photographs were taken just over a week apart, with the load cell reading $280 \mathrm{t}$

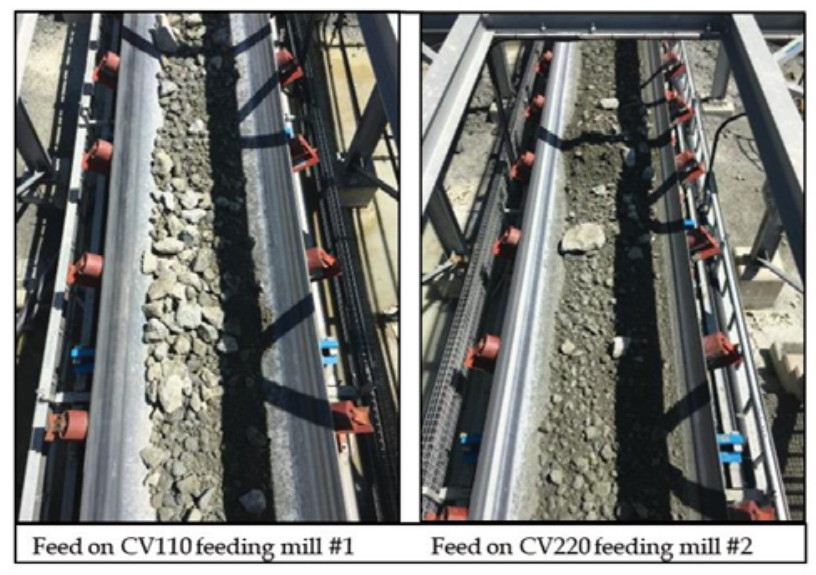

Figure 6-Illustration of the difference in PSD of the feed to mill no. 1 and mill no. 2 due to segregation within the storage silos 


\section{The new Cullinan AG milling circuit - a narrative of progress}

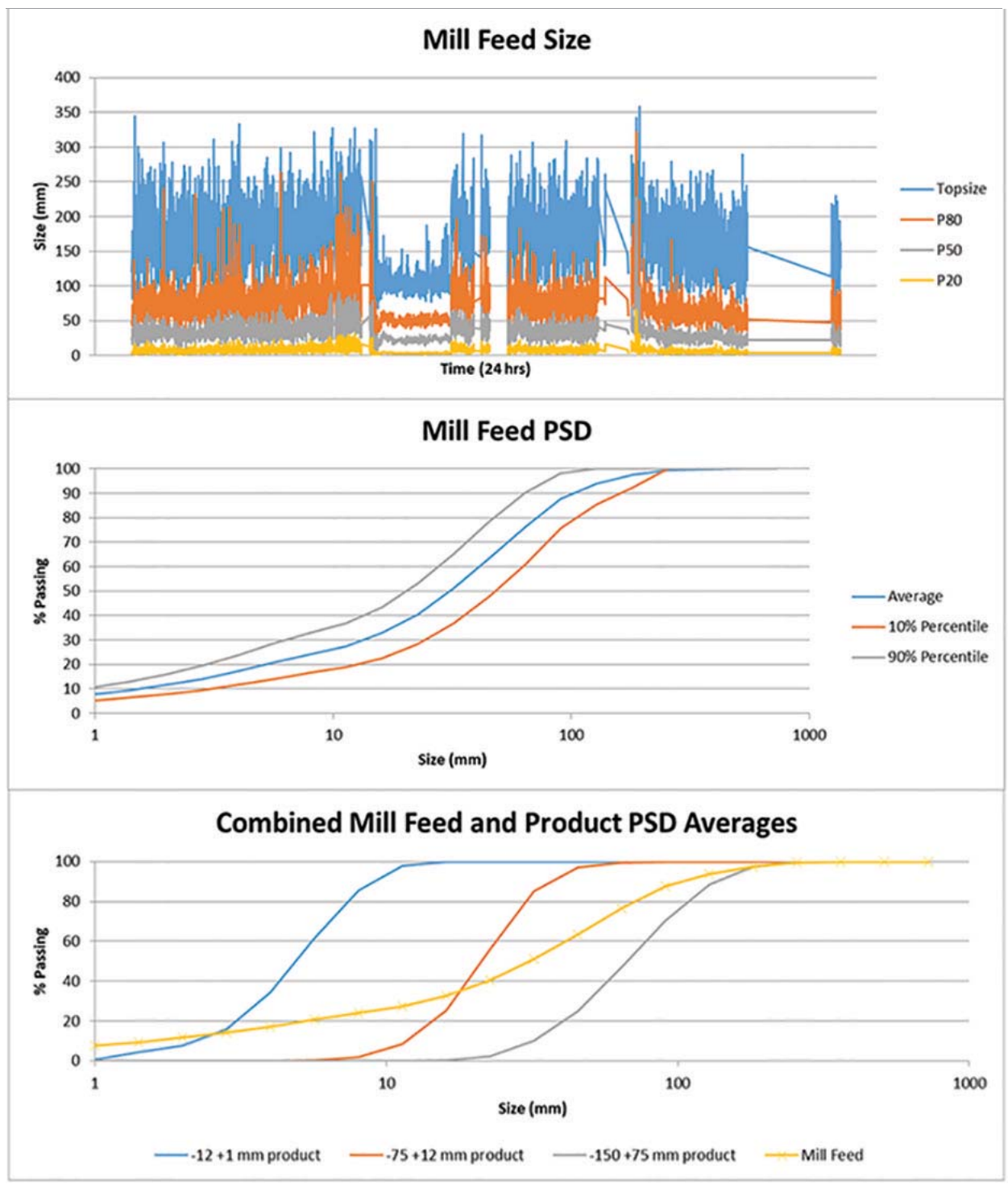

Figure 7-Typical data that can be obtained from the online data analyser, used in this case to analyse each of the mill product conveyor products as well as the mill feed

action to prevent any adverse effect on diamond recovery. The performance of the system is continually verified with physical samples to ensure that the plant can continue to rely on the system.

\section{Getting to understand the CDM AG mill}

Post-commissioning phase, the challenge remains to continue to get the best out the CDM mill circuit. One of the biggest challenges in optimization of an AG mill is the fact that it uses the feed ore as the grinding medium. The loading of grinding medium therefore depends on the feed rate, size, and hardness. When these parameter are highly variable it becomes quite difficult to run the mill under stable conditions (Napier-Munn et al., 1999). In the case of the CDM mill circuit, the feed rate is well controlled and the hardness is not highly variable, as supported by the narrow range of $\mathrm{T}_{\mathrm{a}}$ values in Table II. The feed size is, however, highly variable, as illustrated in Figure 7, which makes it difficult to run the mill under stable conditions.
Understanding the impact of the variability of the feed particle size distribution (PSD) and other mill operating parameters on the immediate mill product was one of the main aims in the early operational stages of the new plant. Below are some of the main lessons learnt about the mill circuit to date

\section{Different milling regimes and operational flexibility}

The results obtained from the various tests done on the mill have indicated that the mill is capable of producing a wide range of product PSDs. An analysis of the mill product showed that the mills can be operated under different milling regimes (Petersen, 2018). The CDM mill circuit can be operated under three different milling regimes, depending on process requirements. These regimes range from gentle milling to aggressive milling, with a transition regime inbetween. The gentle and aggressive regimes established are illustrated in Figure 8. Aggressive milling generates a large percentage of fines $(-1 \mathrm{~mm})$, i.e. $\geq 40 \%$ passing $1 \mathrm{~mm}$ on a 


\section{The new Cullinan AG milling circuit - a narrative of progress}

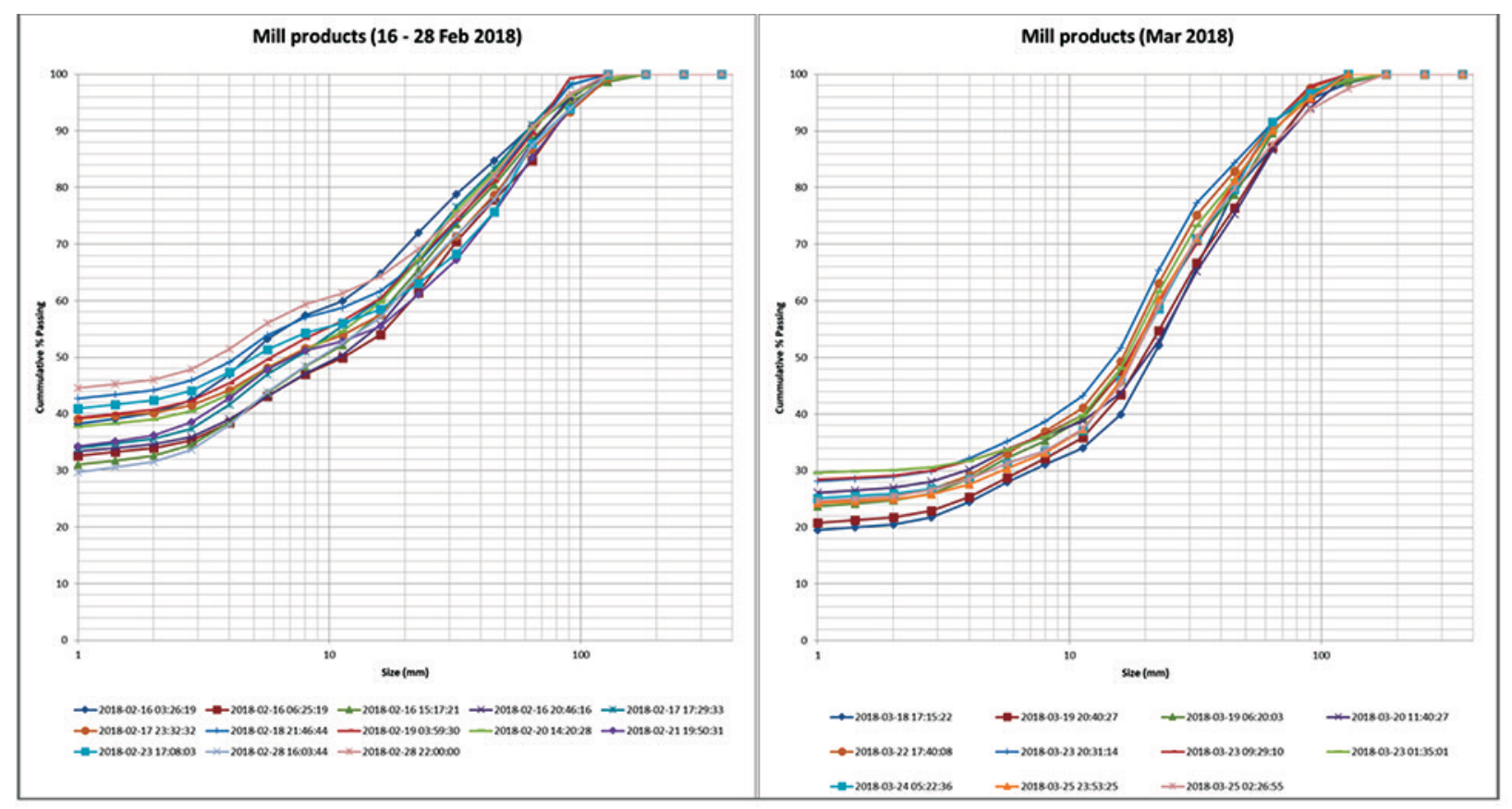

Figure 8-Illustration of different milling regimes. The graph on the left illustrates aggressive milling conditions and that on the right, less aggressive milling

first-pass basis and $\geq 80 \%$ passing $1 \mathrm{~mm}$ on the overall process mass balance. Gentle milling, on the other hand, generates between $20 \%$ and $30 \%$ passing $1 \mathrm{~mm}$ on a firstpass basis.

Aggressive milling was achieved, as illustrated in Figure 8 , on 16-28 February 2018 , while operating the mills at a high percentage of critical speed $(+85 \%)$ and low water-toore ratio set-points $(0.2-0.4)$. Gentle milling, as illustrated in the second diagram, labelled 'March', was achieved at a lower percentage of critical speed (70-85\%) and high water-to-ore ratio set-points $(\geq 0.7)$

The variability of the mill product PSD generated by the different milling regimes directly impacts the mill recirculation load and mill throughput. The average recirculation loads for the gentle and aggressive milling regimes in Figure 8 were calculated to be $180 \%$ and $127 \%$ respectively, which is within the design capabilities of the circuit. The mill circuit was designed to handle recirculation loads of up to $200 \%$. The mill can therefore be operated in the different regimes to cater for the desired product without operating below the design throughput of $750 \mathrm{t} / \mathrm{h}$.

The next step for the CDM production team is to understand the impact of the aggressiveness of the milling regime on other aspects such as diamond liberation, diamond damage, and energy efficiency, in addition to throughput. Efforts to identify the perfect recipe for both mills must take into account the fact that aggressive milling is obtained at high rotational speeds, which may results in more impact damage, while on the other hand gentle milling involves a high recirculation load, which is also not favourable for diamond protection.

The scatter plots in Figure 9 and Figure 10 illustrate some of the insight gained during normal production when the mills were operated under steady-state conditions. Steady state for the purpose of this analysis is defined as instances when the mill was operated at constant feed with the same settings for at least 2 hours. The illustration in Figure 9 shows that the water-to-ore ratio has a strong correlation to the production of $-1 \mathrm{~mm}$ mill product. Lower water-to-ore ratios generally result in the generation of more fines, which is favourable because it allows for higher throughput and reduces recirculation loads and the load on downstream processes.

Figure 10 illustrates that the operating mill load and speed do not have as strong a relationship to grindability as the water-ore ratio, and this is suggested by the linear relationship between speed and power.

The operational flexibility of the new mill plant presents a wide range of options for the operational team compared to the old plant. CDM's goal is to optimize liberation and reduce diamond damage. The insight gained thus far only takes into consideration the ability of the mill circuit to grind the feed to achieve the required throughput and recirculation loads. Future work is required determine the impact of the mill circuit on the final product.

\section{Future work}

Napier-Munn et al. (1999) stress that optimization of an AG mill should never be regarded as complete. It should rather be viewed as an ongoing process which is aimed at ensuring that the circuit is operating at maximum efficiency regardless of other conditions. With this important consideration in mind, current and future work includes the following.

\section{Tightening mill controls}

The CDM production team is currently looking at different options for automated mill control. Some of the options under 


\section{The new Cullinan AG milling circuit - a narrative of progress}

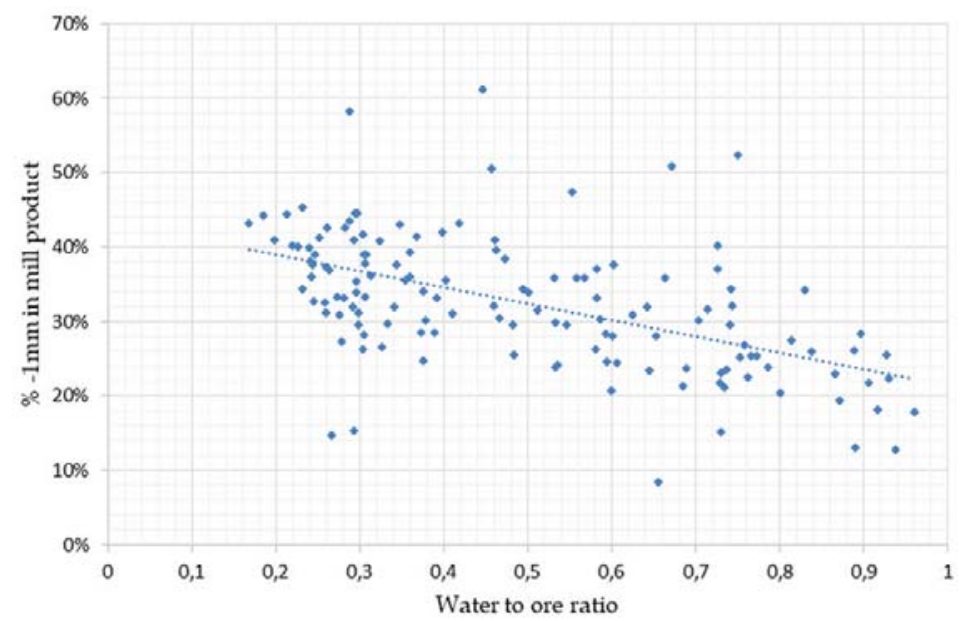

Figure 9-Illustration of the relationship between the fines $(-1 \mathrm{~mm})$ percentage in the mill product vs. the water-to-ore ratio of the feed to the mill

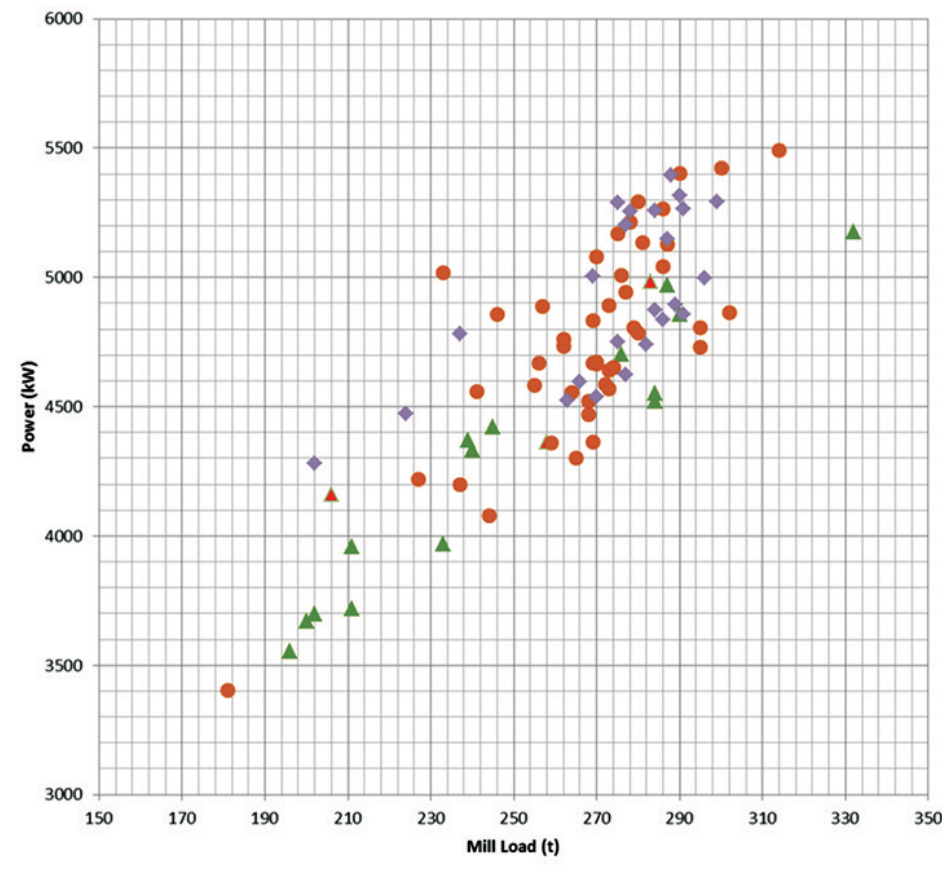

$\Delta$ Mill \#1 - $85<40 \%$ water $\triangle$ Mill \#1 $-85>40 \%$ water $\bullet$ Mill \#1 $-100<40 \%$ water $\bullet$ Mill \#1 - $100>40 \%$ water

Figure 10-Relationship between mill load and power at different water-to-ore ratios

consideration include controls based on DMS feed yield or possible incorporation of the online feed and product PSD monitoring system. The production team is also considering the addition of a field instrument that uses vibration monitoring on the mill bearing housings and mill shell to generate accurate and instantaneous signals of the mill filling levels and the toe angle of the load in the mill (Gugel, Rodriguez, and Gutierrez, 2015) as illustrated in Figure 11. This information is not only essential for optimizomg the throughput of the mills, but can also be used to ensure that the mills are operated in the most diamond comminutionfriendly way.

\section{Optimization with the end product in mind}

The main aim of the CDM mill circuit is to liberate diamonds from kimberlite. The circuit is also specially designed to preserve the value of large diamonds. It is therefore important to optimize the circuit with these goals in mind. Current work involves test work with ceramic simulants and valuation of large diamonds recovered under different milling conditions.

\section{Conclusion}

CDM has successful commissioned their AG milling 


\section{The new Cullinan AG milling circuit - a narrative of progress}

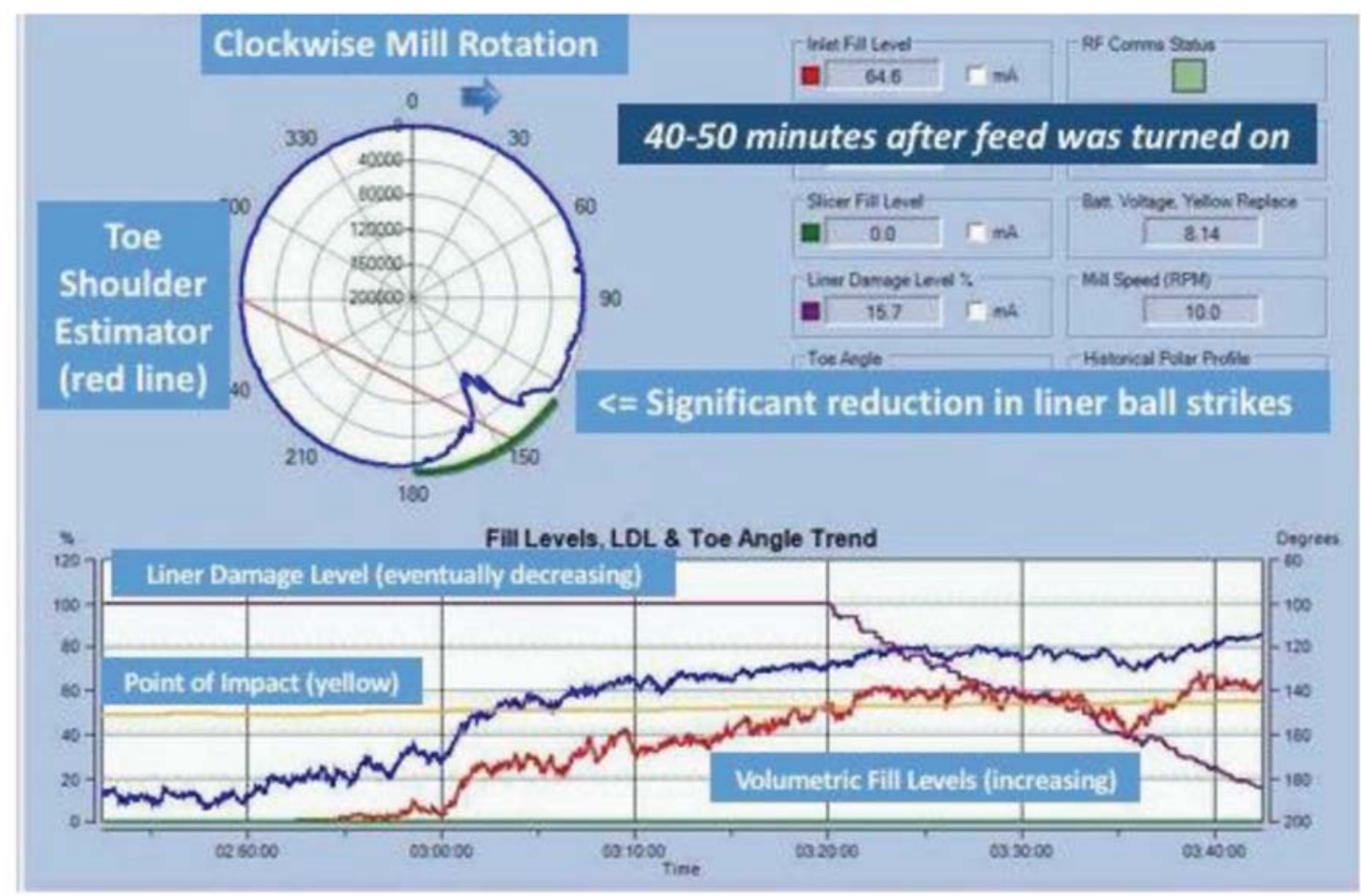

Figure 11-Typical polar plot of data from the vibration monitoring equipment showing impact zone (toe angle) inside the mill (Digital Control Lab, 2018).

comminution circuit treating a relatively competent kimberlitic ore. The commissioning team has thus far managed to achieve the design throughput. The mill circuit is capable of producing a wide range of product PSDs to cater for different production requirements in comparison with a conventional stage-crushing circuit. The challenge now remains to fully understanding the impact of the mill circuit on liberation and diamond damage. Future work will focus on completing the optimization cycle of the circuit. We plan to present this work at subsequent conferences, with the hope of increasing the benchmark of the largest diamond ever recovered.

\section{References}

CLAASSEN, I.C. 2006. Cullinan Diamond Mine - autogeneous milling evaluation. GME Metallurgy Projects Reports. De Beers.

DANIEL, M.J. and MorLey, C. 2010. Can diamonds go all the way with HPGRs? Proceedings of the Diamonds - Source to Use 2010 Conference, 1-3 March 2010. Southern African Institute of Mining and Metallurgy, Johannesburg. http://www.saimm.co.za/Conferences/DiamondsSourceToUse2010/201Daniel.pdf

Daniel, M.J., Bellingan, P., and Rauscher, M. 2016. The modelling of scrubbers and AG mills in the diamond industry and when to use them. Proceedings of Diamonds Still Sparkling, 14-17 March 2016. Southern African Institute of Mining and Metallurgy, Johannesburg.

Digital Control Lab. Not dated. Millslicer. http://www.digitalcontrollab.com/ millslicer.shtml [accessed 15 May 2018].

Gugel, K., Rodriguez, J.C., and L.J. Gutierrez, L.J. 2015. Automated SAG mill speed control using on-contact vibration sensors. Proceedings of the International Conference on Semi-Autogenous and High Pressure Grinding Technology, Vancouver, 20-24 September.
http://www.digitalcontrollab.com/docs/AutoSagControl_MineExpo2016_ v4.pdf

JANSE, A.J.A. 2007. Global rough diamond production since 1870. Gems and Gemology, vol. 43, no. 2. pp. 98-119.

LUCARA DiAmond COMPANy. 2018. http://www.lucaradiamond.com [accessed 10 February 2018].

ME ELECMETAL. 2016. DEM simulation of particle trajectory and discharge behavior. Client presentation.

Napier-Munn, T., Morell, S., Morrison, R., and Kojovic, T. 1999. Mineral Comminution Circuits - Their Operation and Optimization. 2nd edn. Julius Kruttschnitt Mineral Research Centre, University of Queensland.

NTSEle, C. and Sauermann, G. 2007. The HPGR technology - the heart and future of the diamond liberation process? Proceedings of Diamonds Source to Use 2007. Southern African Institute of Mining and Metallurgy, Johannesburg. http://www.saimm.co.za/Conferences/Diamonds SourceToUse2007/010-Sauermann.pdf

Petersen, K. 2018. Cullinan milling project: milling testwork results report. MetalDog Minerals.

Petra Diamonds. 2015. The new Cullinan plant. Company presentation. https://www.petradiamonds.com/wp-content/uploads/Cullinan-PlantPresentation-27-July-2015-FINAL.pdf [accessed 15 March 2018].

SMCC Process Technology. 2014. Review of the proposed twin line AG mill circuit for Petra Diamonds Cullinan underground mine @ 6Mt/a. Indooroopilly QLD, Australia.

STEYN, C.W. 2011. Optimisation of a fully autogenous comminution circuit. MEng thesis, University of Pretoria, South Africa.

VAN NieKerk, L.M., NdLovu, G.N., and SiKWA, N.A. 2013. Commissioning and operating an autogeneous mill at Karowe Diamond Mine. Proceedings of Diamonds-Source to Use 2013. Southern African Institute of Mining and Metallurgy, Johannesburg. pp. 175-192.

WEIER, M. 2013. JKDW \& SMC test report Cullinan Mine. JK Tech, Brisbane. 